\title{
The use of organosilanes to inhibit metal corrosion. A review ${ }^{1}$
}

\author{
M.A. Petrunin, N.A. Gladkikh, M.A. Maleeva, L.B. Maksaeva \\ and T.A. Yurasova
}

\author{
A.N. Frumkin Institute of Physical Chemistry and Electrochemistry, Russian Academy of \\ Sciences, Leninsky pr. 31, 119071 Moscow, Russian Federation \\ *E-mail: lmaksaeva@mail.ru
}

\begin{abstract}
A review of scientific and technical literature on the development of methods for the deposition of organosilicon coatings by modifying metal surfaces with organosilanes before applying an anti-corrosion polymer or paint coating is presented. The review covers scientific and technical information concerning the achievements in the deposition of organosilicon nanolayers on various metal surfaces and their characterization by modern research methods. The choice of organosilanes capable of creating siloxane surface layers that significantly increase the anticorrosive efficiency of a polymer/paint coating, i.e. providing both efficient corrosion protection and high adhesion of the polymer coating to the metal, is considered and justified. The processes that occur upon hydrolysis of organosilanes in aqueous solutions and upon interaction of silanes with a metal surface are considered. The main theories that describe the finishing action of organosilanes at a metal-polymer interface and the hypotheses that explain the mechanism of the formation of metal-siloxane bonds with the surface are presented. The mechanism of the anticorrosive action of siloxane surface layers is considered. The application of surface layers formed on a metal by modification with aqueous solutions of environmentally safe organosilanes for replacement of conversion coatings obtained by surface treatment with toxic hexavalent chromium compounds is discussed. It is shown that corrosion inhibitors are added to modifying aqueous organosilane compounds in order to enhance the anticorrosive efficiency of coatings and to provide the "self-healing" effect. Information on the synergistic effect of mixtures of organosilanes with corrosion inhibitors is provided and the mechanism of synergistic action of the mixtures is discussed.
\end{abstract}

Keywords: organosilanes, corrosion, metals, adhesive compounds, resins, adhesion promoters, sol-gel coatings, corrosion resistance, surface preparation before coating, corrosion inhibitors.

Received: August 10, 2019. Published: October 25, 2019

doi: $\underline{10.17675 / 2305-6894-2019-8-4-6}$

\footnotetext{
${ }^{1}$ This study was supported by the Basic Research Program of the Presidium of the Russian Academy of Sciences No. 34P "Actual Problems of Surface Physicochemistry and Creation of New Composite Materials. 4. Nanostructured coatings for electronics, photonics, alternative energy sources and materials protection", and partially supported by Russian Foundation for basic research, project No. 17-03-00232.
} 


\section{Introduction}

Currently, the problem of reducing losses caused by the corrosion of metal structures is becoming increasingly acute in developed countries. In fact, the costs due to corrosion in industrial countries range from 3.5 to $5 \%$ of the gross national product [1]. In the end of the 20th century and at the beginning of the 21 st century, the total direct costs associated with corrosion in various fields of human activity in the USA amounted to more than $\$ 200$ billion a year, which exceeded 3\% of the annual gross national product. According to the World Corrosion Organization (WCO), the annual global corrosion costs in 2013 amounted to $\$ 2.5$ trillion, which exceeded 3\% of the world GDP [2].

In view of the foregoing, it is obvious that the development of efficient ways for metal corrosion protection is an urgent task.

The use of anticorrosive polymer and paint coatings (PC) is the most popular way to protect metal structures from corrosion [3, 4]. It accounts for more than $90 \%$ of the costs of anti-corrosion measures. The annual production of polymer and paint coatings in developed countries reaches millions of tons. For example, the production of coatings in 1994 amounted to 5.4 million tons in Western Europe and 6.2 million tons in the United States [5].

It is known $[3,6]$ that the protective properties of coatings are largely determined by the strength of adhesive bonds at the metal-polymer interface. In view of this, improving the adhesive properties of protective coatings is a very important scientific and technical task. Currently, various technological processes of surface preparation followed by application of paint and polymer coatings are used in industry for corrosion protection of products made of ferrous and non-ferrous metals [7]. One of the most popular methods for pretreatment of metal surfaces before coating application is "local chemical oxidation" with formulations based on $\mathrm{Cr}^{6+}$ compounds [5]. However, the coatings obtained on their basis do not meet the today's ecological requirements [8]. Moreover, the use of $\mathrm{Cr}^{6+}$ is prohibited in a number of countries and is subject to a complete ban in the future [9].

For this reason, the necessity to develop more efficient and environmentally friendly methods for the pretreatment of metal surfaces arose and attracted the attention of researchers [10]. However, despite the numerous studies [11, 12] dealing with replacement of chromate coatings, an ecologically friendly technology for the pretreatment of metal surfaces has not yet been suggested. Because of that, the development of efficient and ecologically friendly methods for pretreatment of metal surfaces is still an important scientific and technical task.

In recent decades, taking the importance of environmental safety of industrial technologies into consideration, it was suggested to replace chromate pretreatment with treatment of metals in aqueous solutions of organofunctional silanes (organosilanes, trialkoxysilanes or silanes) [13]. This kind of metals treatment followed by application of paint coatings can provide protection against corrosion due to high barrier properties of siloxane films that are formed on the surface. The thickness of these films is from units to 
hundreds of nanometers $[14,15]$, therefore they are referred to as nanocoatings, and the technology for their preparation is referred to as nanotechnology.

\section{General information about the structure and properties of organosilanes}

Organosilanes $\left(\mathrm{R}_{\mathrm{n}} \mathrm{Si}\left(\mathrm{OR}^{\prime}\right)_{4-\mathrm{n}}\right.$ (silanes, or trialkoxysilanes or silane coupling agents [13]) are environmentally friendly [16]. They are commercially available and can form selforganizing siloxane surface nanolayers upon adsorption on metals [17]. For more than 50 years, these compounds have been successfully used to increase the adhesion of a polymer binder to a surface of an inorganic filler in composite materials [18]. Organosilanes are used as adhesion promoters or cross-linking agents in the paint industry. The addition of even a small amount of a silane (0.1-1\%) significantly improves the polymer adhesion to the surfaces of fiberglass, metals, and other inorganic substrates $[13,15,19]$. Organosilanes have the following general formula $[13,15]: \mathrm{R}-\left(\mathrm{CH}_{2}\right)_{n}-\mathrm{Si}-\mathrm{X}_{3}$, where $\mathrm{R}$ is an organofunctional radical containing functional groups and $\mathrm{X}$ is a readily hydrolyzable group, such as chloro-, alkoxy- (methoxy-, ethoxy-), or acetoxy $\left(\mathrm{OCOCH}_{3}\right)$.

Organosilanes have a common name that varies depending on the nature of the hydrolyzable group: trichlorosilane, trialkoxy(ethoxy-, methoxy-)silane, triacetoxysilane. According to the number of readily hydrolyzable groups, alkoxysilanes are divided into several groups, for example, trialkoxysilanes: $\mathrm{R}\left(\mathrm{CH}_{2}\right)_{n}-\mathrm{Si}\left(\mathrm{OR}^{\prime}\right)_{3}$, monoalkoxysilanes $\mathrm{R}\left(\mathrm{CH}_{2}\right)_{n}-\mathrm{Si}\left(\mathrm{OR}^{\prime}\right)$, bis-silanes: $\left(\mathrm{OR}^{\prime}\right)_{3} \mathrm{Si}-\left(\mathrm{CH}_{2}\right)_{n}-\mathrm{R}-\left(\mathrm{CH}_{2}\right)_{m}-\mathrm{Si}\left(\mathrm{OR}^{\prime}\right)_{3}$, where $\mathrm{R}^{\prime}$ is $-\mathrm{CH}_{3}$ or $-\mathrm{C}_{2} \mathrm{H}_{5}$. The organofunctional radical $\mathrm{R}$ in a silane molecule can vary widely and may contain various functional groups (alkyl, vinyl, epoxy, amino, mercapto, ureido, etc.) $[13,15]$, which allowed silanes to be used as adhesion promoters in a wide range of polymer coatings. Silanes were first used to improve the adhesion of a polymer resin to a filler in composite materials $[13-15,18]$. The majority of works related to the promoting action of silanes deal with their interaction with the surfaces of mineral substrates (fillers in composites), such as glass, silicon, silicon oxide, etc. [18]. Treatment with a silane solution can impart a number of valuable properties to the substrate surface, such as hydrophobicity and water resistance [20], superhydrophobicity [21], mechanical strength [22], flame retardant properties [23] and others. In view of this, they are widely used as surface modifiers for various substrates: paper, building materials, leather, glass, fabric, semiconductors, etc. $[14,15,20,23]$. The promotion of adhesion of polymer coatings to inorganic surfaces using organosilanes is performed as follows. An organosilane molecule is bifunctional and is therefore capable of simultaneously interacting both with the surface of an inorganic substrate, for example, a metal, and with the components of a polymer coating [14]. Figure 1 presents schemes that illustrate the mechanism of action of organosilanes for increasing the adhesion of a polymer to an inorganic substrate $[13,23,24]$. When a polymer coating is applied to an organosilane-modified surface, interpenetrating diffusion of the polymer and the components of the organosiloxane layer can occur at the interface, to give the so-called interpenetrating networks [25] that are similar to those shown in Figure 1,e [26] and are responsible for the increase in adhesion. 

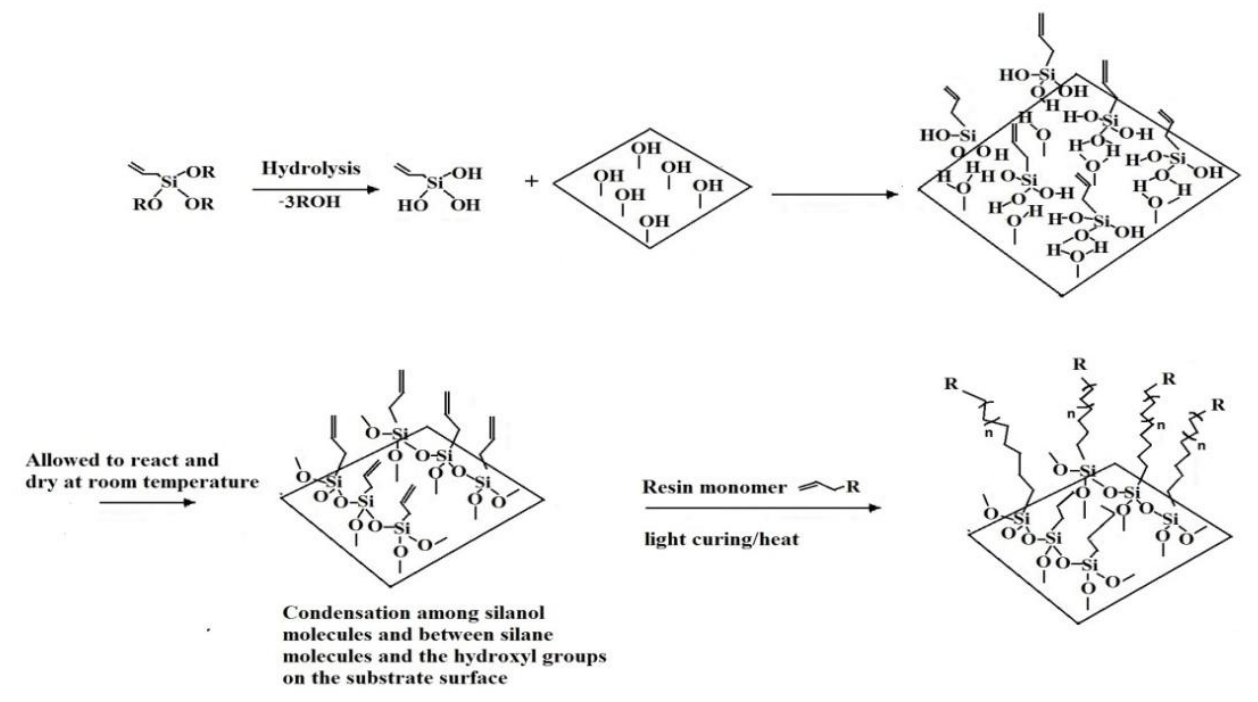

a.

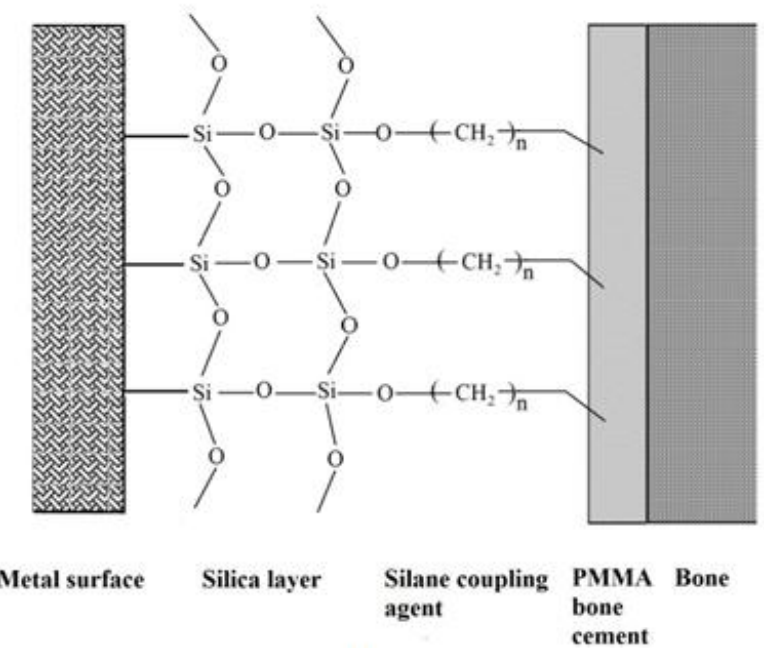

b.

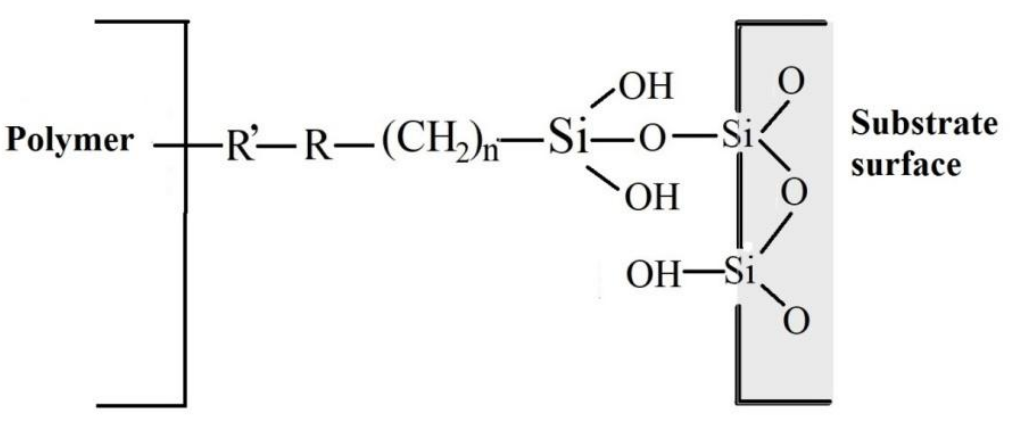

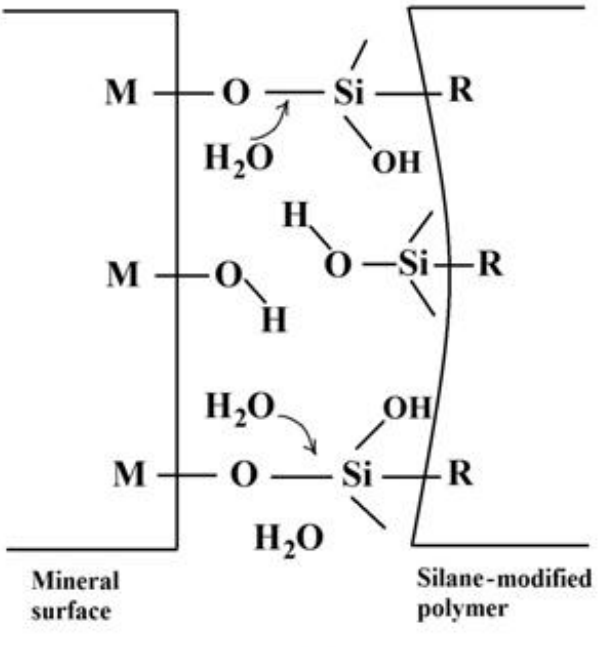

c.

d. 


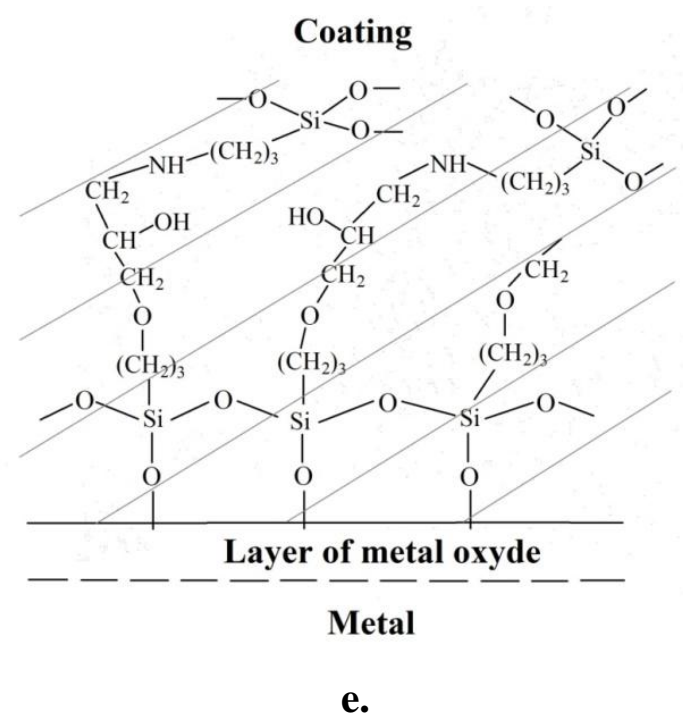

Figure 1. The action of organosilanes as promoters of polymer adhesion to inorganic compounds in accordance with various concepts: a, b [23]; c [27]; d [24]; e [26].

In the last years of $\mathrm{XX}$ century, a number of studies on the chemistry of the interaction of organofunctional silanes with various polymers were conducted [13-15, 24-27]. In fact, the reactions of epoxy oligomers with aminoalkoxysilanes at various temperatures were examined in detail [14, 28, 29]. It was shown that such silanes can be used as efficient hardeners of epoxy resins. It was also shown that an aminosilane is involved in the interactions between a resin and the surface of a solid, which the data of Pluddemann confirmed [13]. It was demonstrated that treatment of glass fibers with organosilicon modifiers containing amino groups resulted in a significant increase in the heat of solidification of the epoxy resin. A similar increase in the exothermic effect was also observed in the solidification of unsaturated polyester resins with benzoyl peroxide in the presence of glass fibers treated with silanes containing styrene or methacrylate groups. Interesting results were also obtained using IR Fourier spectroscopy that takes into account the interaction of the epoxy resin with the anhydride hardener in the presence of $\gamma$-aminopropyltriethoxysilane ( $\gamma$-APS) [29]. Differential spectra show [4] that $\gamma$-APS forms a part of the structure of the hardened epoxy matrix in two ways: 1) by interaction with the epoxy groups of the resin; and 2) by reactions with the carboxy groups of the anhydride hardener.

The synergistic improvement in the properties of the composite achieved upon a simultaneous reaction of acrylic acid with a polypropylene binder and the reaction of the filler with aminosilane indicates that chemical interactions occur in this system [30]. In addition, aminosilanes can catalyze the curing of polymers such as epoxy resin, phenol urea, and melamine resin [6].

The existing mechanisms for increasing the water resistance of organosilane adhesive bonding are based on the assumption that corrosion always precedes a decrease in adhesion $[33,34]$. However, this postulate is one of the most controversial theories of the protective 
effect of organic coatings. Indeed, numerous points of view on this issue exist, from the presence of an aqueous layer on a metal surface, that is, violation of the adhesive bond before corrosion under the coating starts [27,35], to adhesion and corrosion as two independent phenomena [63].

A number of theories have been suggested in the literature to explain the action of silanes at the polymer-substrate interface $[18,28]$, but none of them can give a complete picture of the processes occurring at the interface and explain the beneficial effect of various kinds of treatment on the properties of substrates.

\section{The action of organosilanes at the polymer-substrate interface}

The theory of chemical bonds in substrate-silane-polymer (TCB) systems [18].

The theory of chemical bonding is the earliest and most popular theory that successfully explains the mechanism of processes occurring at the interface. According to it, chemically reactive functional groups of the coupling agent can react with silanol groups on the glass or with hydroxy groups on a metal surface and bind to the substrate through covalent bonds.

In addition, the coupling agent contains at least one more functional group that interacts with the polymer. If these assumptions are correct, then the coupling agent plays the role of a "bond" between the substrate and the polymer resin in the course of curing. Theoretically, this should provide the strongest bond at the interface (with an activation energy of 50-100 kcal/mol). However, the theory of chemical bonding cannot explain all the observed facts observed in the modification of various substrate surfaces. Though the surface treatment of glass [13, 18], $\mathrm{SiO}_{2}[13,15]$ and alumina [67] shows the highest efficiency, good results are also achieved upon modification of talc, clay, as well as aluminum and iron powders $[14,15,19]$. The possible surface bonds of these substrates with a silane layer are unstable against hydrolysis. It is believed that the $\mathrm{Si}-\mathrm{O}-\mathrm{Al}$ and $\mathrm{Si}-\mathrm{O}-\mathrm{Fe}$ bonds can undergo hydrolysis [36]. The activation energy of hydrolysis is $23.6 \mathrm{kcal} / \mathrm{mol}$ and can be reduced to $6 \mathrm{kcal} / \mathrm{mol}$ (i.e., to the energy of hydrogen bonds), for example, by addition of benzoic acid [36]. Moreover, stable polysiloxane films were observed on Au surface [32] with which the formation of covalent bonds is unlikely.

Wettable surface theory [29, 30]

It is believed [29] that the formation of strong adhesion is ensured only in case of good wetting of a substrate surface with an adhesive. It is theoretically possible that when the surface is completely wetted with a polymer resin, the adhesive strength due to physical adsorption would exceed the cohesive strength of the resin. However, since water and other potentially weak boundary layers may be present at the interface under real conditions, physical adsorption cannot provide the necessary adhesive strength [18]. Upon modification of inorganic surfaces with silanes, the latter can improve the surface wettability with a polymer resin. In some cases, the modification even impairs the surface 
wettability. In fact, no relation was found $[13,32]$ between the silage polarity, the wettability of a glass treated with it, and their behavior in a polyester plastic laminate.

\section{Deformable layer theory (DLT) [15]}

The DLT was suggested after the finding that the fatigue properties of laminated plastics are significantly improved upon applying a coupling agent on the glass filler surface. It was assumed that the coupling agent on the interface in a composite is plastic. Considering the resin shrinkage upon curing and the relatively large difference in the thermal expansion coefficients of a glass fiber a the resin in a laminate, in many cases a high shear stress can be expected at the interface in a cured sample. In this case, the role of the coupling agent involves the local relief of this stress. In order to decrease the tension between the resin and fibers without breaking the adhesive bond, the coupling agent should have sufficient relaxation.

The stressed state, structure and properties of the interface layer in the polymermineral substrate system are closely related to the mechanism that controls the transfer of stress in such systems. The mechanical properties of adhesive compounds can be improved in two ways:

1. By forming an interface layer with a mean elastic modulus between the high elastic modulus of the substrate and the low elastic modulus of the organic coating, which provides stress relaxation in the system [32];

2. By providing optimal elasticity of the interface layer, which reduces internal shrinkage and temperature stress at the interface [14].

In both cases, the maximum dependence between the strength of adhesive joints and the elastic modulus in the boundary layer is required. A too high increase in the strength of this layer would make the system brittle, while a too high elasticity would reduce the adhesion strength [14]. Considering the resin shrinkage upon curing and the relatively large difference in the thermal expansion coefficients of a glass fiber a the resin in a laminate, in many cases a high shear stress can be expected at the interface in a cured sample. In this case, the role of the coupling agent involves the local relief of this stress. Therefore, the relaxation of the coupling agent should be sufficient for reducing the tension between the resin and fibers without breaking the adhesive bond.

However, it was shown that the content of silane in the coupling agent is too low for stress relaxation at the interface. Taking this circumstance into consideration, a theory of preferred adsorption was suggested in [15], which is a modified deformable layer theory. The suggested DLT was based on the assumption that different coupling agents on fiberglass vary in the ability to deactivate, degrade, or adsorb some of the components necessary for complete curing from an uncured liquid formulation. This results in local violation of the optimal component ratio due to "preferred adsorption". This effect was believed to play an important role only near the interface, because the separation process depends on the diffusion rates that are rather low in viscous resins. It follows that coupling leads to the 
formation of a resin layer with different thicknesses and flexibility on the interface. This layer can be much thicker than $100 \AA$. In addition, this layer should be ductile and strong in order to provide relaxation and efficient transfer of stress between the stressed fibers.

\section{The bound layer theory $(B L T)[14,15]$}

The interface containing a coupling agent can uniformly transfer stress if its elastic modulus has an intermediate value between the high modulus of the filler and the low modulus of the matrix. The polymer molecules adsorbed on the solid filler particles are packed more densely than in the bulk of the material, and their degree of ordering decreases with the distance from the surface of the filler. The effect of the hardener particles covers a distance of up to $1500 \AA$, within which a gradual change in the mechanical properties of the composite is observed [13].

\section{The theory of reversible hydrolyzed bonds}

This theory was suggested by Pluddemann [32]. It includes the main provisions of the TCB, BLT and DLT theories. The role of silane coupling agents is that when they are distributed over the surface of the filler and form surface layers of polyorganosiloxanes on it, they prevent water molecules from forming phase films or drops on the surface [32]. Although the bonds formed between a coupling agent and a surface are subject to hydrolysis, nevertheless, the reversible nature of this reaction helps the properties of the material to be preserved as long as the integrity of the substrate-coupling agent-polymer matrix interface is preserved [29]. The reversible breakdown and restoration of strained bonds between the coupling agent and the substrate in the presence of water allow stress relaxation without deterioration of adhesion.

Thus, analysis of the literature on the mechanism of the promoting action of silanes has shown that none of the theories suggested so far (and briefly described above) can be preferred for explaining the promoting effect of silanes. TCB in slightly modified form is currently the most popular theory explaining the mechanism of interaction of silanes with the surfaces and the increase in the adhesion of the polymer coatings. Since silane coupling agents are applied on the surface mainly from aqueous or aqueous-alcoholic solutions and the formation of a surface siloxane layer should be attributed to the methods of sol-gel synthesis [37, 39] known for over 100 years [37], it is necessary to consider the changes that organosilanes undergo in aqueous solutions. The tendency of silane modifiers to undergo independent transformations without contact with a solid substrate and a binder had been ignored for a long time [38]. Meanwhile, the structure of an organosilane in a solution has a direct impact on the properties of the adhesive compound formed. It is believed that when aqueous solutions of silanes are used, the interaction with the surface occurs after hydrolysis of a silane to a silanetriol (reaction (1), which undergoes condensation with the surface hydroxy groups [19].

$$
\mathrm{RSi}\left(\mathrm{OR}^{\prime}\right)_{3}+3 \mathrm{HOH}=\mathrm{RSi}(\mathrm{OH})_{3}+3 \mathrm{R}^{\prime} \mathrm{OH}
$$




\section{Chemical behavior of organosilanes in aqueous electrolytes}

Alkoxysilanes undergo a series of chemical transformations involving hydrolysis and condensation in aqueous solutions [19, 34, 37, 39-41]. In [41], the kinetics and mechanism of hydrolysis and condensation of alkoxysilanes in dilute solutions were studied. The hydrolysis kinetics corresponds to the pseudo-first order and the reaction is catalyzed by both bases and acids. It was shown that the hydrolysis of glycidoxypropyltriethoxysilane I ( $\gamma$-GPS) is stepwise, and both $\mathrm{OH}^{-}$and $\mathrm{H}_{3} \mathrm{O}^{+}$can serve as catalysts of the process. The formation of the monosilanol $\mathrm{RSiOH}(\mathrm{OEt})_{2}$ is the slow stage here. Its rate constant depends on the solution $\mathrm{pH}$ and has a minimum at $\mathrm{pH}$ 7.0. It was found that the substitution reaction in case of (hydro)oxide catalysis follows the $\mathrm{S}_{\mathrm{N}}{ }^{* *}-\mathrm{Si}$ or $\mathrm{S}_{\mathrm{N}}{ }^{*}-\mathrm{Si}$ mechanism with a pentacoordinated intermediate [41].

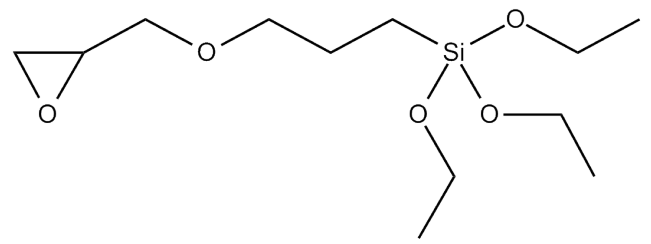

In [41], the hydrolysis of a solution of vinyltriacetoxysilane was studied by nuclear magnetic resonance (NMR). It was found that the $\mathrm{k}_{1} / \mathrm{k}_{2}$ ratio is small. This shows that the first stage of hydrolysis is slow and therefore it is the rate-determining step in the hydrolysis of alkoxysilane. Moreover, the hydrolysis kinetics of alkoxysilane esters in a solvent/water mixture was studied in [13]. The possible factors affecting the hydrolysis of silanes were analyzed, and noted that, first, the hydrolysis reaction occurs spontaneously, and second, both acids and bases accelerate the hydrolysis of silanes, but in different ways. It was noted [41] that acid-catalyzed hydrolysis involves the stage of oxygen protonation of the alkoxy group with a hydrogen ion $\left(\mathrm{H}^{+}\right)$followed by nucleophilic substitution of the remaining groups by the $S_{N} 2$ mechanism. Hydrolysis catalyzed by alkali involves a step of the $\mathrm{Si}$ atom attack with a hydroxide ion to give a five-membered intermediate, followed by a bimolecular replacement of the alkoxy group with a hydroxy group. The rate of hydrolysis by both mechanisms depends on the nature of the alkyl group at the Si atom and on the nature of the alkoxy group. In $[13,41]$ it was found that the hydrolysis rate decreases at a neutral $\mathrm{pH}(\mathrm{pH} 7.0)$; at $\mathrm{pH} 4.0$, the hydrolysis rate is 1000 times higher than at $\mathrm{pH} 7.0$ [14]. In addition, the nature of the group being hydrolyzed [37] affects the rate of the hydrolysis reaction (the rate constant for trimethoxysilaneis $\approx 10$ times higher than that for dimethoxyethoxysilane). The condensation of silanes into siloxanes was studied using NMR spectroscopy [13]. It was shown for GPS that after 0.6 hours at $\mathrm{pH}>4.07$, only the silanetriol is present in the solution (i.e., there are no siloxanes). In silane hydrolysis, the half-reaction time is 3.5 seconds. [13]. Hence, the silanetriol is accumulated in the solution. With an increase in reaction time, the NMR line corresponding to the disiloxane increases, 
and after 23 hours the amount of siloxane becomes comparable with that of silanol. Subsequent condensation to low molecular mass oligomers begins after the solution has been kept for 24 hours. The condensation reaction is also catalyzed by both $\mathrm{H}^{+}$and $\mathrm{OH}^{-}$ ions. The plot of $\mathrm{pH} v s . \log k$ passes through a minimum at $\mathrm{pH} 4$. The epoxy ring can open at low $\mathrm{pH}(\leq 2.15)$, but the effect of the oxirane ring opening on the condensation rate is unknown. The authors suggested the following scheme of condensation into a disiloxane:

$$
\begin{gathered}
\mathrm{RSi}(\mathrm{OH})_{3}+\mathrm{OH}^{-} \underset{\substack{\boldsymbol{k}_{-2} \\
\text { fast }}}{\stackrel{\boldsymbol{k}_{2}}{\rightleftarrows}} \mathrm{RSi}(\mathrm{OH})_{2} \mathrm{O}^{-}+\mathrm{H}_{2} \mathrm{O} \\
\mathrm{RSi}(\mathrm{OH})_{2} \mathrm{O}^{-}+\mathrm{R}^{\prime} \mathrm{Si}(\mathrm{OH})_{3} \underset{\substack{\boldsymbol{k}_{-2} \\
\text { slow }}}{\stackrel{\boldsymbol{k}_{2}}{\rightleftarrows}} \mathrm{RSi}(\mathrm{OH})_{2}-\mathrm{O}-\mathrm{Si}(\mathrm{OH})_{2} \mathrm{R}^{\prime}+\mathrm{OH}^{-}
\end{gathered}
$$

It was found that the reaction had a second order with respect to silanetriol and a first order with respect to $\mathrm{H}^{+}$and $\mathrm{OH}^{-}$ions.

Solutions of organosilanes containing a tertiary amino group have specific properties. These aminosilanes hydrolyze almost instantly in water to give stable dilute solutions. Stable solutions are also formed in polar solvents where the formation of hydrogen bonds is possible, e.g., in alcohols.

It is difficult to explain the stability of aqueous solutions of amino-functional silane coupling agents because amines are catalysts for the polycondensation of silanes into siloxanes and condensation of silanes with the surface hydroxy groups [24]. Moreover, amino-functional silanes can act as self-catalysts in reactions with the filler surface [24], and since it is known [42] that cyclic chelates with 5- and 6-membered rings are very stable, it is assumed that intramolecular siloxanes with internal cyclic amphoteric ions are formed:

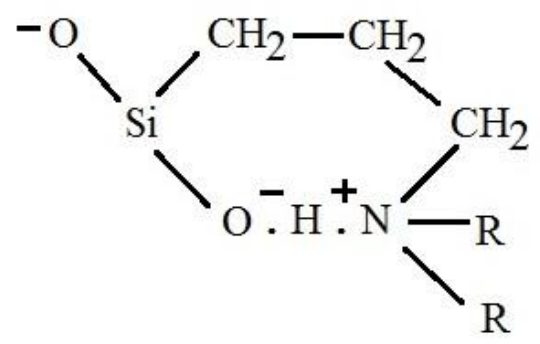

or 


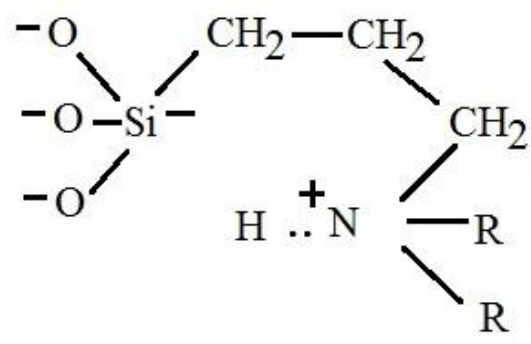

Aqueous solutions of silanes containing primary amino groups are unstable. Insoluble gels precipitate from them, therefore all commercially available amino-containing organosilane adhesion promoters contain tertiary nitrogen.

If the solution contains metal-containing compounds (salts, oxygen-containing compounds) in addition to silanes, then the formation of metal-siloxane complexes is possible. Andrianov and Voronkov et al. [34, 40, 43] studied the formation and properties of metal complexes $(\mathrm{M}=\mathrm{Mg}, \mathrm{Al}, \mathrm{Fe}, \mathrm{Zn}$, etc.) with silanes. The synthesis of metallosiloxanes was carried out by reactions of metal salts (chlorides) with aqueous or organic solutions of silanes. It was found that reaction (4) occurs in an alkaline medium to give metallosiloxanes:

$$
\mathrm{nRSi}(\mathrm{OH})_{2} \mathrm{ONa}+\mathrm{MCl}_{\mathrm{n}} \rightarrow\left[\mathrm{RSi}(\mathrm{OH})_{2} \mathrm{O}\right]_{\mathrm{n}} \mathrm{M}+\mathrm{nNaCl}
$$

The structure of the resulting complexes is shown for aluminum in the scheme below:

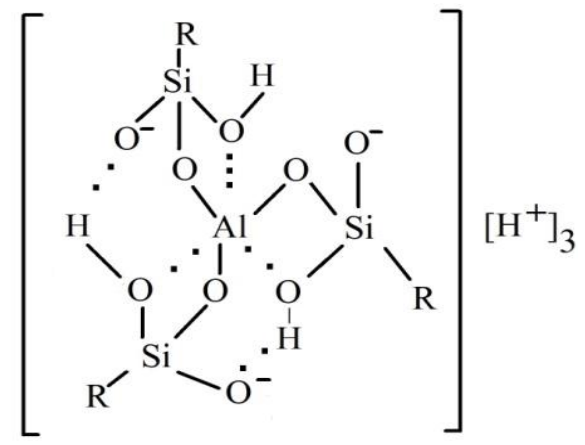

[43]

The stability of this compound depends on the nature of organic radical $\mathrm{R}$ (for example, $\mathrm{C}_{2} \mathrm{H}_{5}$ is less stable than $\mathrm{C}_{6} \mathrm{H}_{5}$ ). A relatively high hydrolytic stability of the $\mathrm{Si}-\mathrm{O}-\mathrm{Al}$ bond was noted for the compounds obtained. Moreover, comparison of the properties of compounds $[\mathrm{RSiO}]_{3} \mathrm{Al}$ and $\left[\mathrm{RSi}(\mathrm{OH})_{2} \mathrm{O}\right]_{3} \mathrm{Al}$ shows that the former is easily hydrolyzed by air moisture, whereas the latter is stable in water, that is believed to be due to the negative inductive effect of the $\mathrm{OH}$ - group that decreases the polarity of the $\mathrm{Al}-\mathrm{O}$ bond. In turn. it complicates the orientation of water molecules at this bond, which is the first stage of hydrolysis [43]. Replacement of the $\mathrm{OH}$ - group with an aliphatic radical causes the opposite effect and facilitates hydrolysis. In addition to alumoorganosiloxanes, 
organosiloxanes of other metals (for example, $\mathrm{Fe}$ and $\mathrm{Mg}$ ) were also obtained. They can be stable in aqueous or aqueous-organic media [34]. In addition, the stability of metal-silicon compounds can be judged by the abundance of natural silicon compounds. It is known [44] that silicate compounds, for example, alumosilicates (muscovite $\mathrm{KAl}_{2}\left[\mathrm{AlSi}_{3} \mathrm{O}_{10}\right](\mathrm{OH})_{2}$, $\mathrm{K}_{4} \mathrm{H}_{4} \mathrm{Al}_{6} \mathrm{Si}_{6} \mathrm{O}_{24}$, nepheline $(\mathrm{Na}, \mathrm{K}) \mathrm{AlSiO}_{4}$, zeolites, etc.) are thermodynamically stable natural minerals.

Thus, silanes undergo fast hydrolysis to silanols in aqueous solutions and subsequently undergo condensation to low molecular mass siloxanes upon prolonged storage of the solution. If metal compounds are present in the solution, metallosiloxane compounds with a $\mathrm{Me}-\mathrm{O}-\mathrm{Si}$ bond that is resistant to hydrolytic breakdown can form.

\section{Adsorption of silanes on a metal surface and formation of bonds with the surface}

It is believed [14, 17, 32, 34, 44] that a silane applied from an aqueous solution interacts with the substrate surface in hydrolyzed form, i.e., in the form of silanetriols. The structure of the silane layer formed on the surface and, accordingly, the mechanical and physical properties of the composites are affected by the following factors: silane structure in the treatment solution, organofunctionality of silanes, drying conditions, substrate surface topology, and chemical state of the surface [29]. The properties of the silane phase on the surface may vary. These properties include the orientation of the silane molecules, the uniformity and thickness of the silane layer, the molecular mass of the fragments of the surface layer, the distribution of molecular mass on the surface, the degree and availability of organic functions for copolymerization with a polymer, the existence of interaction between the surface and radical $\mathrm{R}$ of the silane, the structural gradient and the amount of physically adsorbed silane in the outer layers. When silanes are applied on the surface of mineral fibers, the former are adsorbed on the surface in a multilayered fashion. The films deposited from $0.1-5 \%$ aqueous solutions are 50-200 $\AA$ thick, with a monolayer thickness of 5-10 A. Studies of the physicochemical characteristics of a silane layer on glass fiber showed $[45,46]$ that the coupling agent layer obtained on the glass fiber is "thick" (compared to the size of molecules) and nonuniform, and causes the formation of fiber agglomerates. After extraction of modified fibers with water, about $80 \%$ of the applied coupling agent is removed from the surface, while the remainder is present in the form of islands. It was found using electron microscopy that the surface layer of the coupling agent significantly differs from a monolayer that is characterized by a correct arrangement of molecules (according to the concept of chemical binding). It is believed $[29,46]$ that the film consists of easily removable outer layers and a "tightly" bound polymer near the interface. According to [46], to obtain optimal coupling agent films, a coating of 8 to 70 monolayers should be applied to level off its nonuniformity.

Studies of the adsorption of $\gamma$-aminopropyltriethoxysilane $\left(\mathrm{NH}_{2}\left(\mathrm{CH}_{2}\right)_{3} \mathrm{Si}\left(\mathrm{OC}_{2} \mathrm{H}_{5}\right)_{3^{-}}\right.$ APS- $\gamma$-APS) on glass by radioisotope method using $\mathrm{C}^{13}$ [45] have shown that the silane layer consists of three fractions that differ in water resistance. The main fraction $(98 \%$ of the total amount of the applied coupling agent) is a hydrolysis product of silane physically 
adsorbed on the surface. This fraction can contain up to 270 monolayers and, although it does not dissolve in benzene, it is quickly removed by washing with cold water. The next fraction is a chemisorbed polymerized coupling agent layer containing $~ 10$ molecular layers. Boiling in water for 3-4 hours is required to remove it. After its complete removal, the third fraction remains on the surface, which is apparently most strongly bound to the glass surface. It is approximately a monolayer in which each molecule is bound to the surface by a few bonds.

In $[31,38,46]$, structural transformations of silane coupling agents on glass fiber were studied by Fourier IR technique. The number of molecular layers of the coupling agent on a fiber, the effect of the glass filler and the concentration of the silane solution on the rate of condensation transformations of the coupling agent were determined. The effect of water on the structure of the coupling agent film was considered. Vinyltriethoxysilane $\left(\mathrm{CH}_{2}=\mathrm{CH}-\mathrm{Si}\left(\mathrm{OC}_{2} \mathrm{H}_{5}\right)_{3}\right.$ (VS) was studied. It was found that even upon glass fiber treatment with $0.1 \%$ solution, 60 coupling agent molecules were deposited on $100 \AA^{2}$ of the surface, which corresponded to 15 monolayers. On increasing the solution concentration, the amount of the coupling agent adsorbed on the surface increased and at a concentration of $2 \%$, it reached $615-812 \mathrm{~mol} / \AA^{2}$, i.e., 154-203 monolayers [29]. After evaluating the kinetics of condensation of silane molecules, it was assumed that the monomolecular size of the coupling agent layer on the surface and the limitation of the reactivity of silane groups at deep condensation stages indicate that a spatial polymer, a cross-linked polyorganosiloxane, is formed. Glass fiber accelerates its formation, since in the absence of a filler the condensation of the coupling agent is not so deep [33]. The concentration of the modifying solution also affected the condensation depth of VS [29]. It was found from the changes in the corresponding frequencies in the IR spectrum that, at a solution concentration below 1\%, the condensation of molecules on glass fiber occurs almost completely. At a concentration of $1.5 \%$, the condensation rate slows down abruptly, and at $2-4 \%$, the glass fiber practically ceases to have an activating effect on the mutual condensation of the coupling agent molecules. The authors believe that it is caused by aggregation of the latter in solutions with higher silane concentrations. Starting from $1.5 \%$, micellar aggregation of hydrolyzed VS occurs in the solution [41], which, due to the formation of hydrogen bonds, violates the uniformity of the silane layer, thus preventing the molecules from occupying the positions convenient for subsequent co-condensation.

The silane molecules adsorbed from highly dilute solutions are oriented head-to-head on the surface, which favors their co-condensation. According to [41], condensation is accelerated under the action of a filler due to the regularity of the arrangement of coupling agent molecules in the surface layer. The substrate surface topology affects the ordering of molecules in the adsorbed layers and thus affects the depth of transformations of the coupling agent on the surface.

So, one physically and chemically adsorbed layers on mineral surfaces may be considered. The effect of a physically adsorbed fraction on the mechanical properties of composites has been studied incompletely. In certain cases, an increase in adhesion was 
observed when a physically sorbed silane was removed from the surface [47]. It was shown for an aminosilane in a study of adhesive epoxy compounds [6] that the epoxy resin diffused into the silane layer and a reaction occurred to give a cross-linked polymer, which explained the increase in the adhesion strength. Silane chemisorption is more difficult to study than physical sorption [47]. In the case of chemisorption, it is believed that the sizes of siloxane segments on the surface are determined by the mechanical state of the composite.

A mechanism of the formation of bonds between organosilanes and a metal surface was suggested in [1, 44, 47, 48] (reactions 5, 6):

$$
\begin{gathered}
\mathrm{RSi}\left(\mathrm{OR}^{\prime}\right)_{3 \text { aq }}+\mathrm{H}_{2} \mathrm{O} \rightarrow \mathrm{RSi}(\mathrm{OH})_{3}+3 \mathrm{R}^{\prime} \mathrm{OH} \\
\mathrm{CH}_{2}=\mathrm{CHSi}(\mathrm{OH})_{3}+\mathrm{HO}-\mathrm{Zn}-\rightarrow \mathrm{CH}_{2}=\mathrm{CH}(\mathrm{OH})_{2} \mathrm{Si}-\mathrm{O}-\mathrm{Zn}-
\end{gathered}
$$

In accordance with the above mechanism, silanols formed upon hydrolysis of silane molecules in aqueous solution react with the surface hydroxy groups on the metal to form -Si-O-Me metal-siloxane covalent bonds. Despite the limited options for identifying the resulting bonds, it has now been reliably established that silanes form oxane bonds (MOSi) with mineral surfaces, where $\mathrm{M}=\mathrm{Si}, \mathrm{Ti}, \mathrm{Al}, \mathrm{Fe}$, etc. [43,47]. Such a bond was first discovered in the second half of the twentieth century in [47], where the surface of steel treated with a $1 \%$ GPS solution was studied by secondary ion mass spectroscopy (SIMS). A band corresponding to an ion with a mass of 100 was found In the SIMS spectrum. It was attributed to the $\mathrm{FeSiO}^{+}$fragment, and based on this, the conclusion was made about the formation of $\mathrm{Fe}-\mathrm{O}-\mathrm{Si}$ bonds between the metal oxide and the polysiloxane layer [47]. Some time later, $\mathrm{Fe}-\mathrm{O}-\mathrm{Si}$ and $\mathrm{Cr}-\mathrm{O}-\mathrm{Si}$ bonds were detected using SIMS and XPS [49]. Using Fourier Transform IR spectroscopy (FTIR) for studying the surfaces of metals treated with organosilane solutions, vibration bands of the $\mathrm{Fe}-\mathrm{O}-\mathrm{Si}, \mathrm{Al}-\mathrm{O}-\mathrm{Si}, \mathrm{Cu}-\mathrm{O}-\mathrm{Si}$, and $\mathrm{Zn}-\mathrm{O}-\mathrm{Si}$ fragments were detected $[29,49]$.

Thus, surface treatment with an organosilane solution results in the formation of surface siloxane layers bound to the surface by covalent $\mathrm{Si}-\mathrm{O}-\mathrm{Me}$ bonds.

\section{The effect of surface siloxane layers on metal corrosion}

Since, as shown above, organosilanes can form surface layers on metals $[13,15,18,19,32,37]$, it can be assumed that they can be used for corrosion protection [46]. Figure 2 presents a scheme of the suggested mechanism of the anticorrosive action of a surface siloxane layer [23]. 

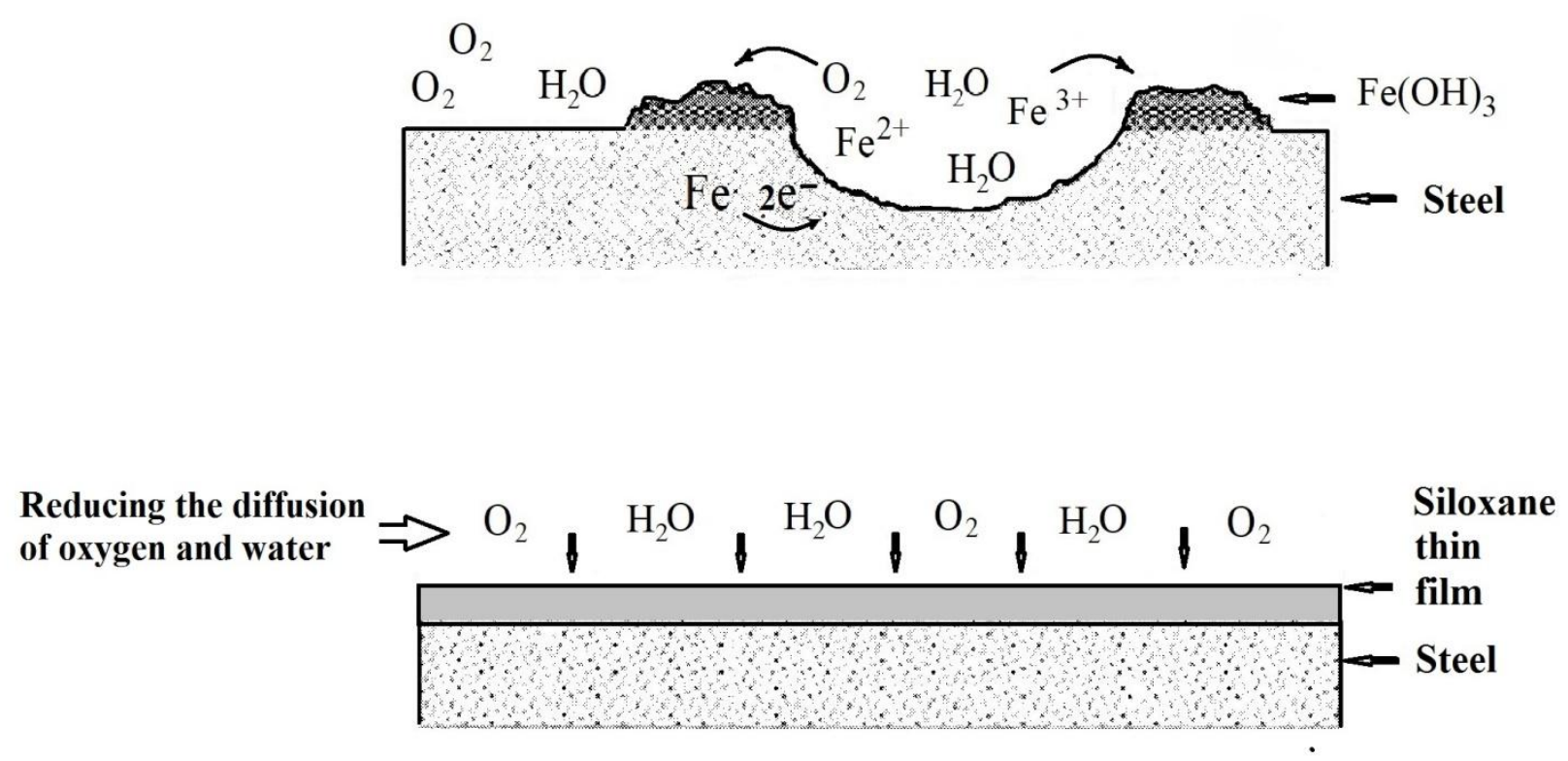

Figure 2. Schematic presentation of the mechanism of metal corrosion and anticorrosive action of a surface silane layer [23].

The first studies on the effect of surface organosilicon layers on metal corrosion were started in the 1980s [50, 51] and continued in the 1990s [28, 29], 2000s [19, 37, 61-63], and 2010s [19, 37, 68, 57-59, 63]. It was shown that surface modification of steel, Al, Mg, and $\mathrm{Zn}$ decreased the rates of anodic dissolution and corrosion of these metals, including those under polymer coatings $[44,50]$. In $[53,54]$, it was shown that inhibition or activation of local (pitting) dissolution of metals could be achieved by changing the charge of a surface organosilicon layer upon incorporation of ionogenic groups into the organic radical of the starting silane. It was shown that in neutral aqueous electrolytes, aminocontaining groups are protonated (reaction $(7), \mathrm{p} K_{\mathrm{a}}=10.0$ ), thus positively charging the metal surface in solutions with near-neutral $\mathrm{pH}$ values.

$$
=\mathrm{N}+\mathrm{H}^{+} \leftrightarrow=\mathrm{NH}^{+}
$$

In accordance with the concept set forth in [1], positive surface charging promotes the adsorption of corrosive chloride ions on the metal surface while negative charging prevents it, thus activating or inhibiting local metal dissolution (pitting). As shown above, positive charging of the surface layer is achieved by protonation of the amino group (reaction 7). Negative charging was provided either by introducing ionic sulfo groups $\left(-\mathrm{SO}_{3} \mathrm{H}\right)$ and imidodiacetate groups $\left(\mathrm{N}\left(\mathrm{CH}_{3} \mathrm{COOH}\right)_{2}\right)$ [53] into the organic radical of the silane molecule. These groups are capable of negatively charging the surface layer upon dissociation by reactions (8) and (9). In the case of surface layers that contain no ionic functional groups but have silanol groups that can dissociate by reaction (10) with $\mathrm{p} K_{\mathrm{a}} 3.0$ [5], the negative charging of the layer is provided by $\equiv \mathrm{Si}^{-} \mathrm{O}^{-}$moieties arising in neutral electrolytes by reaction (9). The authors calculated the surface charge density for organosilicon layers with various ionogenic groups, determined the magnitude of the 
change in the surface $\Psi^{\prime}$ potential, and obtained correlations between the change in the surface potential arising due to different charging of the surface layer and the critical pitting potential of the metal.

$$
\begin{aligned}
-\mathrm{SO}_{3} \mathrm{H} & \rightleftarrows-\mathrm{SO}_{3}^{-}+\mathrm{H}^{+} \\
-\mathrm{CH}_{3} \mathrm{COOH} & \rightleftarrows-\mathrm{CH}_{3} \mathrm{COO}^{-}+\mathrm{H}^{+} \\
\equiv \mathrm{Si}-\mathrm{OH} & \rightleftarrows \equiv \mathrm{Si}-\mathrm{O}^{-}+\mathrm{H}^{+}
\end{aligned}
$$

Since the late 1990s, special attention was paid to the possibility of using bis-silanes to protect metals from corrosion. Bis-silanes differ from mono- and tri-alkoxysilanes in the number of $\mathrm{Si}$ atoms in a molecule and, accordingly, in a large number of readily hydrolyzable groups. For example, six silanol groups are formed in a bis-alkoxysilane molecule upon hydrolysis, in contrast to three silanol groups in the case of trialkoxysilanes and one group for monoalkoxysilanes. In view of this, bis-silanes used as cross-linking reagents can form cross bonds [48] upon polycondensation with the adjacent molecules and form a larger number of $\mathrm{Si}-\mathrm{O}-\mathrm{Si}$ siloxane bonds and $\mathrm{Me}-\mathrm{O}-\mathrm{Si}$ metal-siloxane bonds to form denser cross-linked surface layers. Therefore, we can assume a higher efficiency of bis-silanes in the corrosion protection of metals. Corrosion studies showed that treatment of the metal surface with solutions based on bis-silanes allows $\mathrm{Al}$ and its alloys, $\mathrm{Fe}$ and steel, $\mathrm{Zn}$ and galvanized steel, $\mathrm{Cu}$ and copper alloys, as well as $\mathrm{Mg}$ and its alloys to be protected from corrosion $[48,55]$. The effect of conditions on the formation of the siloxane layer on the metal surface was studied and it was shown that the modification time in the range from $5 \mathrm{~s}$ to $30 \mathrm{~min}$ did not affect the protective properties of a siloxane layer. A study on the effect of the concentration of the modifying solution showed that in the absence of a polymer or paint coating, a relatively thick siloxane layer with good anticorrosion properties was formed on the surface from a 5\% (vol.) modifying solution. The optimum solution for preparing a metal surface before applying a polymer or paint coating has a silane concentration of $2 \%$ (vol.) [55].

It was shown that drying at temperatures about $100^{\circ} \mathrm{C}$ for several hours after treatment of the metal surface in a silanol solution significantly accelerated the formation of siloxane bonds, which can be used to obtain highly crosslinked structures. To increase the efficiency of a siloxane layer, a two-stage process was developed [41]: When treating steel surface with bis(triethoxysilyl)ethane (BTSE), which provides good corrosion protection of the metal, it was established that due to the lack of functional groups in the molecule it is poorly compatible with paint coatings and does not provide the required adhesion to the metal. To increase the adhesion of the polymer coating, an aminecontaining silane ( $\gamma$-APS), a well-known adhesion promoter [13] deposited on a BTSE film, was used. Such a two-layer film is capable of providing both corrosion protection of the metal and adhesion of the paint coating.

The characteristics of siloxane films on metals have been studied using Fourier transform infrared spectroscopy (FT-IR) [13, 23, 25, 29, 31, 38, 46, 49, 54], X-ray 
protoelectron spectroscopy (XPS) [28,35], secondary ion mass spectroscopy (SIMS) [47, 56], atomic force microscopy (AFM) [57], ellipsometry, scanning electron microscopy (SEM), and energy dispersive X-ray spectroscopy (EDX), etc. [58,59]. Using ellipsometry, a nearly linear dependence of the thickness of the bis-aminosilane and bissulfosilane films on stainless steel on the concentration of the corresponding solution was found $[48,49,56]$. In addition, the structure and properties of surface siloxane layers were studied using electrochemical methods [10-12, 16, 19, 26, 37, 44, 48, 50-53, 57], electrochemical pesoquartz nanoweighting (EQCN) [44, 50,57], and electrochemical impedance spectroscopy (EIS) [19, 37, 51].

In [61], the effect of hydrophilic amino groups on the corrosion resistance of a $\gamma$-APS film formed on iron was studied. The previous finding was confirmed that the amino groups in the $\gamma$-APS molecule can compete with silanol groups in the formation of bonds with the surface [54] to produce a hydrophilic surface. Polarization experiments have shown [60] that $\gamma$-APS films formed on iron are unstable in water. It has also been shown that the amino group may accelerate the penetration of corrosive $\mathrm{Cl}^{-}$into the film, causing passivity breakdown and development of pitting metal dissolution, as was observed previously and was related to a positive charging of the surface layer [52, 53].

In [61], using polarization and impedance studies, it was shown that layers based on an alkylamine with addition of an alkylchlorosilane had an inhibitory effect on the corrosion of iron in $0.1 \mathrm{M}$ and $0.5 \mathrm{M} \mathrm{NaCl}$ solutions. A combination of 1,2-bis(trichlorosilyl)ethane and octadecyltrichlorosilane with an amine were used. As a result, the inhibitory efficacy increased by more than $97 \%$ [62]. In [64], the inhibition of local and general corrosion of iron in $0.1 \mathrm{M} \mathrm{KClO}_{4}$ with addition of $\mathrm{Cl}^{-}$was studied. Selforganizing monolayers were formed on the metal surface based on 16-hydroxyhexadecanate ion $\left(\mathrm{HO}\left(\mathrm{CH}_{2}\right)_{15} \mathrm{CO}_{2}^{-}\right)$modified with the following silanes: 1,2-bis(triethoxysilyl)ethane (BTSE) and octadecyltriethoxysilane. The presence of a siloxane layer on the surface was shown to increase the time until the passive film breakdown to 48 hours. In addition, it was shown that the breakdown time increased with decreasing logarithm of the $\mathrm{Cl}^{-}$ion concentration.

In [44], the specific features of formation and the anticorrosion properties of siloxane monolayers based on vinyltriethoxysilane (VS), glycidoxypropyltriethoxysilane (GPS), aminopropyltriethoxysilane (APS), and other compounds on Al were studied. It was found that covalent bonds with the surface (AlOSi) are formed in the presence of water adsorbed on aluminum surface. The presence of a siloxane monolayer on Al surface decreases the adsorption of water and inhibits the hydration of the metal oxide film. Negative charging of the siloxane layer due to dissociation of the silanol group (reaction (9) reduces the adsorption of $\mathrm{Cl}^{-}$and inhibition of local metal dissolution $[52,53]$. On the other hand, due to the acceleration of $\mathrm{Cl}^{-}$adsorption on the metal surface in the case of a positively charged siloxane layer, for example, if $\gamma$-APS is used, the localized corrosion of the metal in a chloride-containing electrolyte is activated [51-53]. 
It was noted in [63] that methacryloxypropyltrimethoxysilane inhibits $\mathrm{Al}$ corrosion in $\mathrm{NaCl}$ solutions, and in [64] that 3-trimethoxysilylpropanethiol-1 reduces the corrosion of $\mathrm{Cu}$ and carbon steel in chloride-containing solutions due to the formation of a polymer passive film consisting of aluminum oxides and siloxanes that is formed upon chemical condensation between silanols and aluminum oxides and prevents the diffusion of chloride ions.

EIS was used to determine the corrosion resistance of aluminum alloys modified with solutions of the following alkoxysilanes: GPS and methylglycidoxypropyltriethoxysilane (MGPS). It was shown that the best results were achieved with MGPS [48].

In addition, the effect of bis-sulfosilane on the corrosion of an $\mathrm{Al}$ alloy was studied by potentiodynamic methods and EIS [48]. It was shown that corrosion occurs under cathodic control due to alkalization of the near-electrode layer. It was found that corrosion inhibition is due to the presence of a dense, highly crosslinked surface layer that effectively blocks areas where cathodic processes can occur [19]. Studies of the corrosion resistance of an Al alloy and hot dip galvanized steel after treatment with a bis-sulfosilane, a bisaminosilane and their mixture by SEM methods showed that the hydrophilic bisaminosilane does not provide good corrosion protection. If the hydrophobic bis-sulfosilane is used, high-quality protective films on $\mathrm{Al}$ are obtained, though they have low efficiency on hot dip galvanized steel. The latter is explained by the heterogeneity of the film on hot dip galvanized steel due to poor wetting of the oxide-coated $\mathrm{Zn}$ surface with the modifying solution. Localized corrosion begins in defective areas not covered with a siloxane film [19]. It is noted that the use of a mixture of a bis-sulfosilane and a bis-aminosilane in 3:1 ratio greatly increases the corrosion resistance of $\mathrm{Al}$ and hot dip galvanized steel, which is achieved using a mixture of silanes due to selective compensation of the drawbacks of individual mixture components.

Siloxane layers obtained by treating the metal surface with silane solutions whose molecules have long aliphatic chains (for example, $n$-octadecyl(trimethoxy)silane can significantly improve the barrier properties of a siloxane coating efficiently inhibit $\mathrm{Al}$ corrosion [54]. Unlike other organosilanes, the surface layers obtained from $n$ octadecyl(trimethoxy)silane have good covering capacity [65]. A study of the electrochemical behavior of phosphated steel treated with a BTSE solution showed an inhibitory effect comparable to, or even greater than that obtained using chromate conversion coatings [66].

The effect of treating the surface of an Al alloy with a solution of amino- and vinylsilanes on the performance of an epoxy coating was studied by wetting angle measurements. It was found that treatment with a silane solution significantly increases the free surface energy of the treated samples. The nature of interaction between the silane film and aluminum substrate was studied by FTIR spectroscopy. The formation of two bond types was found: metal-siloxane bonds between the silane and $\mathrm{Al}(\mathrm{Si}-\mathrm{O}-\mathrm{Al})$ and siloxane bonds $(\mathrm{Si}-\mathrm{O}-\mathrm{Si})$ between the adjacent silane molecules on the surface. The resulting 
siloxane film is not a monolayer since its thickness is significant, approximately $100-200 \mathrm{~nm}[19]$.

The effect of pretreatment of $\mathrm{Al}$ and $\mathrm{Cu}$ surfaces with silanes on the adhesion of a paint coating (a polyester powder coating) was estimated by measuring the adhesion under dry and wet conditions and by determining the time of the start of peeling of the coating under special environmental conditions [67]. In addition, the properties of the samples were analyzed using FTIR, SEM, and EIS. Improved performance was shown for samples of $\mathrm{Al}$ and $\mathrm{Cu}$ coated with a siloxane film compared to samples treated with a fluo-zirconate solution [67].

Thus, analysis of literature has shown that siloxane surface layers formed on metals upon modifying them in organosilane solutions can not just increase the adhesion of a polymer coating applied on a metal but also efficiently inhibit metal corrosion as successful competitors with environmentally harmful chromate coatings.

\section{Combined use of organosilanes and corrosion inhibitors}

It is known that during chromatography, chromate ions can diffuse in the aqueous medium to the damaged area and be included in the film, providing restoration of the damaged areas (the so-called "self-healing" effect $[16,19,68]$. Siloxane layers, unlike chromate coatings, do not provide such an effect that they can be a significant drawback, since in operational conditions the integrity of the surface layer is possible due to mechanical damage, such as scratches, tears. In places where layer integrity is disturbed, corrosion processes that are especially dangerous can occur, given the small area of defects compared to the total area. The ability of the surface layer to self-healing could significantly reduce the risk of corrosion occurring in defects in the surface layer. The literature provides information on eliminating this drawback by filling the siloxane films with corrosion inhibitors and developing the so-called modified siloxane or silane films $[19,69]$.

So, in [19], sodium octylthiopropionate was introduced into a BTSE film on iron, which effectively inhibited the corrosion of iron in an artificially made defect ("notch") of the surface layer in an aerated sodium chloride solution. Using polarization and impedance measurements, the self-healing ability of the modified siloxane film in a chloridecontaining solution was discovered [19]. In addition, a significant increase in the effectiveness of the action of corrosion inhibitors when used in conjunction with organosilanes was shown in [37,68-71]. For example, the introduction of cerium acetate into a modifying solution based on $\gamma$-aminopropyltriethoxysilane leads to a decrease in the $\mathrm{pH}$ of the modifying solution, an increase in the surface tension and wetting of the modified samples from $\mathrm{Al}$ and steel, and to a significant decrease in their corrosion rate $[19,37]$. The most effective is the surface layer obtained upon metal modification with an organosilane solution with the addition of $3 \%$ cerium acetate [72].

When copolymerizing glycidoxypropyltrimethoxysilane with tetraethylorthosilicate tetra(n-propoxy)zirconate, particles of zirconium oxide $\mathrm{ZrO}_{2}$ with a size of $40-200 \mathrm{~nm}$ 
were obtained. The formation of such particles depends on $t$ and the time of the hydrolysis/condensation of zirconate $[19,37]$. The formed sol-gel coating has enhanced corrosion protection, probably due to clogging of the pores with zirconium oxide. The atomic ratio of $\mathrm{Zr} / \mathrm{Si}$ in the film is from 1:4 to 1:9.

The introduction of nanosized particles of $\mathrm{SiO}_{2}$, a salt of vanadium acid and hexafluorosilicic acid (or its salt) into the organosilane modifying solution leads to the formation of a surface layer that protects metals from corrosion [19].

The study of a two-layer film formed on an Al alloy upon metal modification with a solution of cerium (III) salts followed by treatment with a BTSE solution showed that the cerium conversion coating promotes better crosslinking of the siloxane layer and, thus, improves its protective ability [19].

In $[19,68]$, information is presented on the processes occurring on the surface of galvanized steel. Solutions of bis-sulfosilane for processing electro-galvanized steel were supplemented with cerium and zirconium nitrates, and for the treatment of hot-galvanized steel with cerium and lanthanum nitrates, as well as cerium and titanium oxides. The surface morphology of these coatings was studied by AFM and SEM. To process hot dip galvanized steel, an aqueous solution of BTSE and other silanes was modified with $\mathrm{SiO}_{2}$ nanoparticles. The protective properties of the obtained layer were studied using SEI, potentiodynamic polarization, and others [19].

In $[48,58,73]$, to increase the anticorrosive efficiency of layers formed from solutions of BTSE and some other silanes, zinc oxide nanoparticles, $\mathrm{SiO}_{2}$, and carbon fiber were introduced into the solution.

Using energy dispersive X-ray analysis and reflection-absorption IRS, the dependence of the film quality ( $\gamma$-GPS) on the surface of carbon steel on the temperature and time of formation was established. The film formed at $150^{\circ} \mathrm{C}$ for $1 \mathrm{~h}$ has maximum adhesion. It was found that $t$ exerts a great influence on the chemical structure of the film [1].

The EIS method was used to study the behavior of siloxane films formed on steel from solutions of triaminosilane and bisaminosilane with and without alkyd LCP, in particular, the effect of layer curing time on the barrier properties of the surface layer [74].

A study of the factors affecting film adhesion $(\gamma-\mathrm{GPS})$ on the surface of mild steel showed that it is affected by the solvent, hydrolysis time, solution concentration, and film formation $t$. The optimal conditions for the surface layers obtained on the basis of $\gamma$-GPS were established): water-methanol solution of silane, hydrolysis time $48 \mathrm{~h}$, solution concentration $10 \%$, layer formation $t 150^{\circ} \mathrm{C}$ for $1 \mathrm{~h}$ [19].

\section{Conclusion}

Thus, protective coatings formed upon surface modification with organosilane solutions on metals and alloys can significantly increase the corrosion resistance of the latter in various corrosive environments and are promising for wide practical application. It can be expected that in the near future, carcinogenic chromate coatings on structural metals will be replaced by environmentally friendly siloxane layers, since they can not only inhibit metal 
corrosion, but also give the surface useful properties, such as resistance to oxygen, water and other environmental components. In addition, siloxane layers are capable of interacting with components of polymer or paint coatings and increasing the strength of metalpolymer adhesive bonds. As an environmentally friendly technology, the formation of surface layers based on silanes is very promising in terms of replacing environmentally harmful chromate coatings that are prohibited in many countries.

To increase the anticorrosive efficiency and provide the "self-healing" effect of coatings, corrosion inhibitors, in particular, compounds of rare-earth elements and cerium, are added to the modifying aqueous solutions of organosilanes.

\section{References}

1. E. McCafferty, Introduction to Corrosion Science, Springer, New York - Dordrecht Heidelberg. - London, 2010, p. 4. doi: 10.1007/978-1-4419-0455-3

2. A.M. El-Sherik, Trends in Oil and Gas Corrosion Research and Technologies, Woodhead Publishing, 2017, p. 12.

3. W.V. Baeckmann, W. Schwenk and W. Prinz, Cathodic Corrosion Protection. Theory and Practice of Electrochemical Protection Processes, 3th Edition, Gulf Publishing Company, Houston, TX USA, 1997, p.8.

4. D. Stoye and W. Freitag, Paints, Coatings and Solvents, Willey-VCH, Weinheim New York - Chichester - Brisbane - Singapore - Toronto, 1998, p.2. doi: $\underline{10.1002 / 9783527611867}$

5. R. Lambourne and T.A. Strivens, Paint and surface coatings. Theory and Practice, Second edition, Woodhead Publishing Ltdm, Cambridge, England, 1999, 784 pp.

6. W. Funke, The role of adhesion in corrosion protection by organic coatings, JOCCA, 1985, 68, no 9, p.229-232.

7. L.K. Wang, N. Shammas and Y.-T. Hung, Waste treatment in the metal manufacturing, forming, coating and finishing industries, CRC Press, Taylor \& Francis Group, Boca Raton, FL, USA, 2009, 494 pp.

8. H. Osborne, K.Y. Blohowiak, S.R. Taylor, G.P. Bierwagon, B. Carlson, D. Bernard and M.S. Donley, Testing and evaluation of nonchromated coating systems for aerospace applications, Prog. Org. Coat., 2001, 41, 217-225. doi: 10.1016/S03009440(01)00132-1

9. White Paper Strategy for a Future Chemical Policy of the Commission of the European Communities, Brussels, 2012, Directive 2011/65/EU of the European Parliament and of the Council.

10. G. Buchheit, H. Guan, S. Mahajanam and F. Wong, Active corrosion protection and corrosion sensing in chromate-free organic coatings, Prog. Org. Coat., 2003, 47, 174-182. doi: $10.1016 /$ j.porgcoat.2003.08.003

11. R.L. Twite and G.P. Bierwagen, Review of alternatives to chromate for corrosion protection of aluminum aerospace alloys, Prog. Org. Coat., 1998, 33, no 2, p.91-100. doi: $\underline{10.1016 / \mathrm{S} 0300-9440(98) 00015-0}$ 
12. Yu.P. Avdeev, V.A. Karpov, L.B. Maksaeva and M.A. Petrunin, Chromate-free passivation of aluminum alloys for paint repair technologies, Int. J. Corros. Scale Inhib., 2014, 3, no 3, 198-203. doi: 10.17675/2305-6894-2014-3-3-198-203

13. E.P. Pluddemann, Silane Coupling Agent, 2nd Edition, Springer Science+Business Media New York, 1991, 253pp. doi: 10.1007/978-1-4899-2070-6

14. V.A. Ogarev and S.L. Selector, Organosilicon promotors of adhesion and their influence on the corrosion of metals, Prog. Org. Coat., 1992, 21, 135-187. doi: 10.1016/0033-0655(92)87003-S

15. A.I. Mikhalsky, Organofynktsional'nye apprety $\mathrm{v}$ napolnennykh polimerakh (Organofunctional apprets in filled polymers), Itogi nauki i techniki, VINITI, 1984, 151-223 (in Russian).

16. M. Salasi, T. Shahrabi, E. Roayaei and M. Aliofkhazraei, The electrochemical behaviour of environment-friendly inhibitors of silicate and phosphonate in corrosion control of carbon steel in soft water media, Mater. Chem. Phys., 2007, 104, 183-190. doi: $10.1016 /$ j.matchemphys.2007.03.008

17. J. Gun, J. Sagiv, On the Formation and Structure of Self-assembling Monolayers, III. Time of Formation, Solvent Retention, and Release, J. Colloid Interface Sci., 1986, 112, 457-472. doi: 10.1016/0021-9797(86)90114-1

18. P.W. Erickson and E.P. Plueddemann, Composite Materials, Eds.: L.J. Broutmann and R.H. Krock, 6, Interfaces in polymer matrix composites, Ed.: E.P. Plueddemann, Academic Press, NY, London, 1974, 1-29.

19. V.V. Mensikov, A.A. Kalinkina, D.V. Mazyrova, E.F. Akimova and T.A. Vagrayan, Primenenie vodnykh rastvorov silanov dlya podgotovki poverchnosti metalla pered naneseniem lakokrasochnych pokrytii (Application of aqueous solutions of silanes to prepare the metal surface before applying paint coatings), Korroz.: mater., zashch. (Corrosion: materials, protection), 2010, no. 4, 30-36 (in Russian).

20. M.G. Voronkov and N.V. Shorokhov, Vodoottalkivayushchie pokrytia $v$ stroitelstve (Waterproof coatings in construction), AN Latv. SSR, Riga, 1963, 180 pp. (in Russian).

21. S.V. Gnedenkov, V.S. Egorkin, S.L. Sinebryukhov, I.E. Vyalyi, A.S. Pashinin, A.M. Emelyanenko and L.B. Boinovich, Supergidrofobnye kompozitsionnye pokrytiya na poverkhnisti magnievogo splava (Superhydrophobic composite coatings on the surface of magnesium alloy), Vestnik DVO RAN, 2013, 5, no. 171, 3-11 (in Russian).

22. S.M. Silverstrovich and M.A. Boguslavskii, Povyshenie prochnosti stekla v rezultate ego obrabotki kremniiorganichimi soedineniyami (Increasing the strength of glass as a result of its processing with silicon compounds), DAN SSSR, 1959, 129, no. 6, 1362-1370 (in Russian).

23. Silane. Chemistry, applications and performance, Eds.: K. Moriguchi and S. Utagawa, Nova Science Publishers, Inc. NY, 2013, p. 93.

24. B. Arkles, Silane coupling agents. Connecting across boundaries, Gelest, Inc. Morrisville, PA, USA, 2014, p. 2. 
25. K. Hoh, H. Ishida and J.L. Koenig, The diffusion of epoxy resin into a silane coupling agent interphase, In Composite Interface, Ed.: J.L. Koenig, Elseview, 1986, 251-263.

26. M.A. Petrunin, A.P. Nazarov, R.M. Zaitsev and Yu.N. Mikhailovskii, Phase interactions in a system composed of a metal and anticorrosive siloxane coatings, Prot. Met., 1991, 26, no. 5, 587-592.

27. E.P. Plueddemann, Bonding through coupling agents in Molecular Characterization of Composite Innterfaces, Eds.: H. Ishida and G. Kumar, Springer Science+Business Media, New York, 1985, 13-25. doi: 10.1007/978-1-4899-2251-9

28. D.J. Ondrus, F.J. Boerio and K.J. Grannen. Molecular Structure of Polymer/Metal Interphases, J. Adhes., 1989, 29, 27-42. doi: 10.1080/00218468908026475

29. H. Ishida, Recent progress in the studies of molecular and microstructure of Interfaces in composites, coatings and adhesive joints in Adhesion Aspects of Polymeric Coatings, 2hd Edition, Ed.: K.L. Mittal, Plenum Press, NY-London, 2011, 45-107. doi: $10.1007 / 978-1-4613-3658-7$

30. P.E. Cassidy and B.J. Yager, Coupling agents as adhesion promoters, J. Macromol. Sci., Rev. Polym. Technol., 1971, 1, 1-49. doi: 10.1080/03602557108545009

31. C.-H. Chiang, H. Ishida and J.L. Koenig, The structure of $\gamma$ aminopropyltriethoxysilane on glass surfaces, J. Colloid Interface Sci., 1980, 74, no. 2 , 396-404. doi: 10.1016/0021-9797(80)90209-X

32. E.P. Plueddemann, Adhesion Through Silane Coupling Agents, J. Adhes., 1970, 2, no. 3, 184-201. doi: $10.1080 / 0021846708544592$

33. P.E. Koch and D.J. Schenck, A study of silane coupling for commercially bonding dissimilar thermoset materials, Silane and other coupling agents, Ed.: K.L. Mittal, VSP, Utrecht Netherlands, 1992, 541-547.

34. M.G. Voronkov, Advances in Organosilicon Chemistry, Mir Publishers, Moscow, 1985, p. 268.

35. T.R. Bullet, Wet adhesion and corrosion, JOCCA, 1986, 69, p. 44.

36. E.P. Plueddemann, Silane Adhesion Promoters for Polymeric Coatings in Adhesion Aspects of Polymeric Coatings, 2nd Edition, Ed.: K.L. Mittal, Plenum Press, NYLondon, 2011, 363-379. doi: 10.1007/978-1-4613-3658-7

37. G.P. Wang and J.P. Bierwagen, Sol-gel coatings on metals for corrosion protection, Prog. Org. Coat., 2009, 64, 327-338. doi: 10.1016/j.porgcoat.2008.08.010

38. H. Ihida, S. Naviroy and J.L. Koenig, The influence on the surface characteristics of silane layers, Physicochemical Aspects of Polymer Surfaces, Ed.: K.L. Mittal, N.Y. Plenum, 1984, 91-104. doi: 10.1007/978-1-4615-7584-9

39. Sol-gel technology for thin films, fibers, preforms, electronics, and specialty shapes, Ed.: L.C. Klein, Noyes Publications, Park Ridge, New Jersey, U.S.A., 1988, p. 407.

40. M.G. Voronkov, V.P. Milishkevich and Yu.A. Yuzhelevskii, Siloksanovaya svyaz' (Siloxane bond), Nauka, Sibirskoe otdelenie, Novosibirsk, 1976, 413 pp. (in Russian). 
41. R. Pohl and F.D. Osterholtz, Kinetics and mechanism of aqueous hydrolysis and condensation of alkyltrialkoxysilanes in Molecular characterization of composite interfaces, Eds.: H. Ishida and G. Kumar, Springer Science+Business Media, New York, 1985, 157-170. doi: 10.1007/978-1-4899-2251-9

42. I.S. Kanan, W. Tze and C. Tripp, Method to double the surface concentration and control the orientation of adsorbed (3-Aminopropyl) dimethylethoxysilane on silica powders and glass slides, Langmuir, 2002, 18, 6623-6627. doi: 10.1021/la0203133

43. K.A. Andrianov, Metody elementoorganicheskoi chimii. Kremnii (Methods of elementoorganical chemistry. Silicon), Nauka, Moscow, 1968, p. 24 (in Russian).

44. M.A. Petrunin, A.P. Nazarov and Yu.N. Mikhailovski, Formation mechanism and properties of thin siloxane films on metal surfaces, J. Electrochem. Soc., 1996, 143, no. 1, 251-257. doi: 10.1149/1.1836417

45. M.E. Schrader, Radioisotope Studies of Coupling Agents at the Interface, In Composite Materials, Eds.: L.J. Broutmann and R.H. Krock, 6, Interfaces in polymer matrix composites, Ed.: E.P. Plueddemann, Academic Press, NY, London, 1974, 110-131.

46. H. Ishida and J.L. Koenig, Fourier-Transform infrared spectroscopic study of the silane coupling agents/porous silica interface, J. Colloid Interface Sci., 1978, 64, no. 3, 555-564. doi: 10.1016/0021-9797(78)90398-3

47. M. Gettings and A.J. Kinloch, Surface Characterization and Adhesive Bonding of Stainless Steels. I - The Surface Characterization of the Steels, Surf. Interface Anal., 1979, 1, no. 5, 165-172. doi: 10.1002/sia.740010506

48. V. Palanivel, D. Zhu and W.J. van Ooij, Nanoparticle-filled silane films as chromatereplacements for aluminum alloys, Prog. Org. Coat., 2003, 26, 384-392. doi: 10.1016/j.porgcoat.2003.08.015

49. J.P. Jolivet, E. Chaneac and E. Tronc, Iron oxide chemistry, From molecular clusters to extended solid network, Chem. Commun., 2004, no. 5, 481-483. doi: $\underline{10.1039 / \mathrm{B} 304532 \mathrm{~N}}$

50. M.A. Petrunin, A.P. Nazarov and Yu.N. Mikhailovski, Adsorption and interphase interactions in metal - silane and metal - silane - polymer systems, Prot. Met., 1993, 29, 225-231.

51. V.A. Ogarev and S.L. Selector, Organosilicon promotors of adhesion and their influence on the corrosion of metals, Prog. Org. Coat., 1992, 21, 135-187. doi: 10.1016/0033-0655(92)87003-S

52. M.A. Petrunin, V.D. Gil'dengorn and A.P. Nazarov, Anionic aluminum activation in the presence of adsorbed ion exchangers, Prot. Met., 1994, 30, no. 2, 130-136.

53. M.A. Petrunin, V.D. Gil'dengorn, T.A. Yurasova, G.P. Kudryavtsev, A.P. Nazarov and G.V. Lisichkin, Effect of the surface charge on the corrosion resistance of aluminium and magnesium in electrolytes containing chlorides, Prot. Met., 66, no. 9, 1323-1328.

54. F.J. Boerio and R.G. Dillingham, Hydrothermal stability of titanium/epoxy adhesive joints, In Adhesive Joints, Ed.: K.L. Mittal, Plerenum Press, 1984, 541-553. doi: $\underline{10.1007 / 978-1-4613-2749-3}$ 
55. E.R. Pohl and A. Chaves, Sterically hindered silanes for waterborne systems: a model study of silane hydrolysis. Silanes and other coupling agents, Ed.: K.L. Mittal, VSP Utrecht, Netherlands, Boston, USA, 2004, 3, 3-10.

56. W.J. van Ooij and A. Sabata, Characterization of films of organofunctional silanes by TOFSIMS and XPS. Part I. Films of N[2-(vinylbenzylamino)-ethyl]-3-aminopropyltrimethoxysilane on zinc and $\gamma$-aminopropyltriethoxysilane on steel substrates, In Silane and other coupling agents, Ed.: K.L. Mittal, VSP, Utrecht Netherlands, 1992, 323345. doi: $\underline{10.1002 / \text { sia.740200522 }}$

57. M.A. Petrunin, L.B. Maksaeva, T.A. Yurasona, N.A. Gladkikh, E.V. Terechova, V.A. Kotenev, E.N. Kablov and A.Yu. Tsivadze, Adsorption of vinyl trimethoxysilane and formation of vinyl siloxane nanolayers on zinc surface from aqueous solution, Prot. Met. Phys. Chem. Surf., 2016, 52, no. 6, 964-971. doi: 10.1134/S2070205116060150

58. T.F. Child and W.J. van Ooij, Application of Silane Technology to Prevent Corrosion of Metals and Improve Paint Adhesion, Trans. IMF, 1999, 77, no. 2, 64-70. doi: $10.1080 / 00202967.1999 .11871249$

59. N.A. Gladkikh, Yu.B. Makarychev, M.A. Maleeva, M.A. Petrunin, L.B. Maksaeva, A.A. Rybkina, A.I. Marshakov and Yu.I. Kuznetsov, Synthesis of thin organic layers containing silane coupling agents and azole on the surface of mild steel. Synergism of inhibitors for corrosion protection of underground pipelines, Prog. Org. Coat., 2019, 132, 481-489. doi: 10.1016/j.porgcoat.2019.04.004

60. V. Subramanian and W.J. van Ooij, Effect of the amine aunctional group on corrosion rate of iron coated with films of organofunctional silanes, Corrosion, 1998, 54, no. 3, 204-215. doi: $10.5006 / 1.3284845$

61. N. Tsuji, K. Nozawa and K. Aramaki, Ultrathin protective films prepared by modification of an N,N-dimethylalkylamine monolayer with chlorosilanes for preventingcorrosion of iron, Corros. Sci., 2000, 42, no. 9, 1523-1538. doi: 10.1016/S0010-938X(00)00010-X

62. K. Aramaki, Prevention of iron corrosion at scratched surfaces in $\mathrm{NaCl}$ solutions by thin organosiloxan polymer films containing octylthiopropionate, Corros. Sci., 2000, 42, no. 11, 2023-2036. doi: 10.1016/s0010-938x(00)00037-8

63. K. Aramaki and T. Shimura, Prevention of passive film breakdown and corrosion of iron in $0.1 \mathrm{M} \mathrm{KClO}_{4}$ with and without $\mathrm{Cl}^{-}$by covering with an ultrathin twodimensional polymer coating and healing treatment in $0.1 \mathrm{M} \mathrm{NaNO}$, Corros. Sci., 2010, 52, no. 9, 2766-2772. doi: 10.1016/j.corsci.2010.03.036

64. M. Ghiazza, A.M. Beccaria, G. Poggi and G. Castello, Corrosion inhibitive mechanism of silane coupling agent 3-(trimethoxysilyl)propanethiol-(l) for mild steel in sodium chloride solutions, Br. Corros. J., 1994, 29, no. 3, 210-214. doi: $\underline{10.1179 / 000705994798267593}$ 
65. A. Frignani, F. Zucchi, G. Trabanelli and V. Grassi, Protective action towards aluminium corrosion by silanes with a long aliphatic chain, Corros. Sci., 2006, 48, no. 8, 2258-2273. doi: $10.1016 /$ j.corsci.2005.06.018

66. D. Susac, C.W. Leung, X. Sun, K.C. Wong and K.A.R. Mitchel, Comparison of a chromic acid and a BTSE final rinse applied to phosphated 2024-T3 aluminum alloy, Surf. Coat. Technol., 2004, 187, no. 2-3, 216-224. doi: 10.1016/j.surfcoat.2004.03.017

67. F. Deflorian, S. Rossi and L. Fedrizzi, Silane pre-treatments on copper and aluminium, Electrochim. Acta, 2006, 51, no. 27, 6097-6103. doi: 10.1016/j.electacta.2006.02.042

68. F. Brusciotti, D.V. Snihirova, H. Xue, M.F. Montemor, S.V. Lamaka and M.G.S. Ferreira, Hybrid Epoxy-silane coatings tor improved corrosion protection of Mg alloy, Corros. Sci., 2013, 67, 82-90. doi: 10.1016/j.corsci.2012.10.013

69. P. Balan, M.J. Shelton, D.O.Li Ching, G.Ch. Han and L.K. Palniandy, Modified silane films for corrosion protection of mild steel, Procedia Mater. Sci., 2014, 6, 244-248. doi: 10.1016/j.mspro.2014.07.030

70. Yu.I. Kyznetsov, A.M. Semiletov, A.A. Chirkunov, I.A. Arkhipushkin, L.P. Kazanskii and N.P. Andreeva, Gidrofobizatsiya poverkhnosti alyuminiya stearinovoy kislotoy i trialkoksisilanami dlya zashchity ot atmosfernoy korrozii (Hydrophobization of aluminum surface with stearic acid and trialkoxysilanes for protection against atmospheric corrosion), Zhurnal fizicheskoy khimii, 2018, 92, no. 4, 512-521 (in Russian). doi: 10.7868/S0044453718040015

71. N.A. Gladkikh, Yu.B. Makarychev, M.A. Maleeva, M.A. Petrunin, L.B. Maksaeva, A.A. Rybkina, A.I. Marshakov and Yu.I. Kuznetsov, Synthesis of thin organic layers containing silane coupling agents and azole on the surface of mild steel. Synergism of inhibitors for corrosion protection of underground pipelines, Prog. Org. Coat., 2019, 132, 481-489. doi: 10.1016/j.porgcoat.2019.04.004

72. C. Shivane, N.B.V. Simhadii and W.J. van Ooij, Improved water-based silane pretreatment for hot-dip galvanized steel substrates, Silane and other coupling agents, Ed.: K.L. Mittal, VSP, Leiden Netherlands, Boston USA, 2007, 4, 253-275.

73. D. Xue, Z. Tan, M.J. Schulz, W.J. van Ooij, J. Sankar, Y. Yun and Zh. Dong, Corrosion studies of modified organosilane coated magnesium-yttrium alloy in different environments, Mater. Sci. Eng., 2012, 32, 1230-1236. doi: 10.1016/j.msec.2012.03.013

74. B. Chico, J.C. Galván, D. de la Fuente and M. Morcillo, Electrochemical impedance spectroscopy study of the effect of curing time on the early barrier properties of silane systems applied on steel substrates, Prog. Org. Coat., 2007, 60, no. 1, 45-53. doi: 10.1016/j.porgcoat.2007.06.007 